fibroid growth. The cervix was large, high up, and unaffected by the disease; and the enlarged body of the uterus could be felt above forming the tumour which distended the abdomen. The sound entered along the anterior surface of the growth for five inches. The bleeding had been continuous for some time. Half a grain of sclerotic acid was injected under the skin of the abdomen twice a week; the bleeding began to lessen, and at the end of five or six weeks she had intervals of ten to fourteen days free from hæmorrhage, alternating with bleeding epochs of similar duration. At the end of three months the bleeding epochs had become still shorter and the intermenstrual intervals prolonged to nearly three weeks. The use of sclerotic acid was then discontinued for a month and the bleeding became profuse and almost continuous. Recourse was had again to the use of sclerotic acid with the effect of diminishing the hæmorrhage. She improved in health, gained strength and colour, and was able in August to go to her friends in the country, and stay there a month. During this time the acid was not nsed, and after her return to London the hæmorrhage began again. The acid was again used as before, and with similar effect. At the end of February, 1878, she complained of much bleeding, pain in the back, and bearing-down, - pains she had never suffered before. On examination the cervix uteri was found dilated and a portion of the tumour projecting through it into the vagina. This was removed, and the use of sclerotic acid continued some time longer. Portions of the tumour have been removed on two occasions since. The pieces removed were soft and oedematous. At this time the tumour seemed to have diminished in size, for it reached only to the umbilicus. I was not then aware of the alternate increase and diminution in the size of fibroids, so that I attributed to the effect of the acid more than perhaps was due. For the last eighteen months the acid has only been occasionally used, for the catamenia have not been very frequent or profuse, though still excessive. I have since repeatedly observed that the tumour diminishes at the begin ning of and with menstruation, and grows again gradually during the intermenstrual period.

The following are the measurements during the last month: She menstruated from 15th Jan. to 23rd Jan. On February 7 th the tumour reached three inches above the umbilicus. On the 10th it reached four inches above the umbilicus. She began to menstruate on the 9 th, but very scantily; and on the 11th the upper border of the tumour was three and a quarter inches above the umbilicus, on the 13th two and three-quarter inches.

CASE 3.-H. W- aged forty-four years, a widow, was admitted on November $7 \mathrm{th}, 1879$, into University College Hospital. She has always enjoyed good health. She has been married eleven years, and has never been pregnant. The catamenia appeared first about the thirteenth year, and returned every four weeks, lasting each time two or three days. In February of this year she had a profuse flooding, but since that time the flow has been somewhat less. During the intermenstrual intervals she is usually quite well, but occasionally she has noticed a little yellow discharge. She never suffers from nausea or vomiting, and is free from pain. She first noticed the swelling in the abdomen about two years ago, and says "it flattens after each menstruation." She was well developed, well nourished, but pale; the mucous membranes were very anæmic. There was a systolic murmur audible over the heart and great vessels at the root of the neck, but loudest over the third left costal cartilage; otherwise the heart and lungs appeared healthy. In the lower part of the abdomen was ielt a smooth, rather hard, oval-shaped (but with a slight notch in its upper border) tumour. It rose from the pelvis, was somewhat more prominent and reached a little higher on the left than on the right side of the median line. On the right it appeared flattened out, and was less defined than on the left. On November 8th she said that she daily expected her courses, and thought that she was a couple of days after her proper time; she added, "I am now much bigger, but I shall be quite flat when the courses are over." The vagina was relaxed, the cervix hard and thickened. The os uteri was much larger than is usual in nulliparze, and was pushed forward. Behind the uterus was a hard, smooth, round body, continuous with the uterus and with the tumour in the abdomen. It was freely movable with the uterus, which was in front of the growth, and not tender. The sound could be introduced for four inches and a half in front of the tumour, and a little to the left side, to the highest part of the swelling in the abdomen, so that the left prominence was the fundus uteri. This part reached to within an inch and a half of the umbilicus. On Nov. 9th the highest part of the tumour reached within two inches and a half of the umbilicus-that is, it was one inch lower than on the previous day. In the evening, at 11 o'clock, the menstrual flow made its appearance, so that the decrease in the size of the swelling took place nine hours previous to the appearance of the flow (the visit being made at 1.30). On the 10th and 11th the flow was very profuse; between 4 P.M. on the 10 th and the morning of the 11th nine large drawsheets were soaked through, and on the latter date the distance between the umbilicus and the upper border of the tumour measured three inches, only half an inch more than nine hours before the flow appeared. The distance remained unchanged till the end of menstruation on Nov. 18th. Then the sound was introduced, and the length of the uterine cavity was found to be three inches, an inch and a half less than on the day previous to the commencement of menstruation. During this timethat is, from her admission on Nov. 7th till Nov. 18th-she was put upon no treatment, so that nothing interfered with the natural course of the growth. On this day (the 18th) a hypodermic injection of sclerotic acid (half a grain) was given, and on the following day (I9th) the distance of the upper border of the tumour from the umbilicus was four inches and a half, and on the 20th three inches and a half. The hypodermic injection was repeated on the 21st, and on the following day this distance had increased to five inches. On the 24th the distance had diminished to four inches and a half, and the length of the uterine cavity as measured by the sound was found to be three inches. From this time to Dec. 5th the distance gradually diminished as follows :Nov. 26th, distance from upper border of tumour to umbilicus, $3 \frac{3}{4}$ in. On the $27 \mathrm{th}, 3 \frac{1}{2}$ in.; on this day there was a slight discharge of blood-two or three small clots. On the $28 \mathrm{th}$, the distance was $3 \frac{1}{3}$ in. On Dec. 1st, 3 in. On the 3 rd, 3 in.; no discharge of any kind; hypodermic injection of sclerotic acid. On the 5 th, the distance was in the morning, 23 in.; hypodermic injection given; distance in the evening, $3 \frac{1}{4}$ in. On the $7 \mathrm{th}, 4$ in. On the 8 th, $3 \frac{1}{2}$ in. On the 11 th the distance in the morning was $3 \mathrm{in}$.; sound enters $3 \frac{3}{1}$ in. ; abdomen somewhat fuller; distance in the evening, $3 \mathrm{in}$. to $3 \frac{1}{2}$ in. On the 13 th, the distance in the afternoon was $4 \frac{1}{1}$ in.; does not feel well ; menstruation began. On the 15th, the distance was 4 in., menstrual flow much less than usual. On the $16 \mathrm{tb}$, the distance was $3 \frac{1}{2}$ in. On the $17 \mathrm{th}$, $3 \frac{1}{2}$ in. On the 18th, 4 in. On the $20 \mathrm{th}, 4$ in. On the $22 \mathrm{nd}$, 4 in.; menses have been not at all excessive. On the 27 th, the distance was $3 \frac{1}{2}$ in. On Jan. 1st, $3 \frac{1}{2}$ in. So that throughout the interval, despite the sudden decrease which followed injections of sclerotic acid, there was a gradual increase in the size of the tumour, and an equally sudden diminution before or about the commencement of menstruation.

(To be concluded.)

\section{9 attirut}

\section{HOS PITAL PRACTICE,}

\section{BRITISH AND FOREIGN.}

Nulla autem est alia pro certo noscendi via, nisi quamplurimas et morborum et dissectionum historias, tum aliorum, tum proprias collectas habere, et inter se comparare.-Moвga gN De Sed. et Caus. Morb., lib. iv. Proœmium.

\section{ST. THOMAS'S HOSPITAL.}

[EYE DEPARTMENT.]

CASES OF TEMPORARY AFFECTION OF ONE OPTIC NERVI:, COMPARABLE TO BELL'S PARALYSIS OF THE FACIAL.

(Under the care of Mr. NeTtLeship.)

CAsEs such as those given below are instances of a small but well defined group of cases in which the affection of the optic nerve is in several of its clinical characters similar to the common cases of facial paralysis attributed to the influence of cold. The failure of sight sets in quickly (though not suddenly), affects only one eye, is accompanied by slight inflammatory appearances at the dise, and is usually followed by complete recovery. There is very often pain on the same side of the head, generally "neuralgic" or "rheumatic." 
The disease is described by Leber (Graefe-Saemisch's "Handbuch ") as due to a temporary and slight inflammation of the trunk of the nerve behind the eyeball. Mr. Nettleship said that he had now seen a considerable number of these cases, but believed the disease to be much less common than paralysis of the facial nerve. His patients had all been between about twenty and thirty-five, he had seen no cases in children or old people. He believed the disease did not relapse, and never attacked the second eye, but it was very interesting that one of the cases here given had recently recovered from facial paralysis; it did not seem probable that this optic nerve disease could be caused by cold. Mr. Nettleship remarked that cases of rapid failure of one eye sometimes with gross neuritis, ending in permanent blindness, were also met with, but thought it more useful to consider them for the present as distinct from the present group.

CASE 1. - James $\mathrm{G}$ ligent man, of half Irish parentage, employed in the Westminster Aquarium, had for two or three years been an occasional patient on account of old granular lids, contracted when a boy at Forest-gate School. He had some hypermetropia and astiomatism, and an old convergent squint of the left eye, with defective sight from suppression. $\mathrm{He}$ wore a cylindrical glass for his working eye at one time, but found after a while that he could do as well without it. At the time the attack narrated below came on he had ceased attending school for about two months. His vision before the attack was taken more than once, when glasses were tried. On May 14th, 1878, it was : Right $=\frac{21}{40}$, and with $\frac{1}{18}$ spherical convex combined with $+\frac{1}{36} \mathrm{cyl}=\frac{2}{3}$, well. Left had convergent strabismus; read 20 Jaeger with difficulty; had been practically blind for a long time. On Sept. 5th the sight of the right (good) eve began to fail, and by the 9 th he "could not see anything." When he went to the hospital on the 10th only 18 Jaeger could be seen with difficulty, and the optic disc was very indistinct and hazy. Five grains of iodide of potassium were given three times a day. On the 17th the sight had already much improved. Vision $=\frac{2}{70}$, and 8 Jaeger could be read at from six to ten inches; not much improved by glasses. The disc of right eye was congested and hazy veins enlarged and somewhat tortuous; pupil active. Left eye (strabismus and old defect) : Dise healthy. On the 26th the sight was much better. Vision $=\frac{20}{50}$; slowly improved to $\frac{20}{4} \frac{0}{0}$ Read 1 Jaeger fairly at from six to eight inches, unaided. On Oct. 3rd vision was the same; disc still too red its border not clear, and the veins distended.

The visual field was not taken, nor was he tested for colours. Probably, however, there was some defect for red (i. e., central scotoma), for when the attack came on he found he could not tell gold from silver, nor "bright scarlet from brickdust." Even as late as Oct. 14th, when he considered himself quite well, he described "a slight mist or whitish tint" on objects, as if the centre of the field were not perfectly restored. For several days before the sight began to fail he had pain, chiefly of a dull character, but sometimes shooting, on the same (right) side of the head, passing behind the ear and to the back of the neck. $\mathrm{He}$ "thought it was a stiff" neck." At the same time the eyeball was (according to his statement) reddened, and though not spontaneously painful, would hurt him if he looked up and to his left, "as if the eye was strained." $\mathrm{He}$ also noticed as peculiar at the time that he was "sweating so freely in the head," but did not think it was unilateral.

On the evening before the failure he had been saying to his companions how good his sight was, and had tested it by counting a long line of gas jets at a distance. This may be borne in mind in reference to the possible influence of dazzling by bright light in determining a change in the optic nerve. It may be added that the patient was not subject to stiff neck, nor had he ever had facial or any other paralysis. His father had for twenty years been an inmate of an asylum for "recurrent mania," attributed to a fall on the hoad.

CASE 2.-E. W. G-, aged thirty-three, a wheelwright, tall, strongly built, rather pale, with dark hair, was under the care of Dr. Greenfield for right facial paralysis for nearly a year before Mr. Nettleship saw him. It was attributed to sleeping in a lieen draught, was treated by galvanism, and recovery was very nearly, if not quite, perfect when Dr. Greenfield sent him to Mr. Nettleship (on Oct. 10th, 1878) for examination of his left eye, which had recently failed.

The man's account of his eye symptoms was as follows. On Sept. 26th he complained to Dr. Greenfield of "flashes of light" in the left eye, followed by pain passing over to the back of the head. On the $291 \mathrm{~h}$, whilst reading, he cradually became aware of some defect of sight, and found that it was in the left eye. The exact rate of failure after this was not noticed. The same shooting pain continued, especially when he made sudden movements of the head or eye. He noticed also after the defect came on, that the left eye was not "so wide open" as the right.

Oct. 10th, 1878. - Vision : Right $\frac{2}{2} 8$, and 1 Jaeger at six inches, refraction normal ; left, only counts fingers, seeing them best at periphery of field, especially above and below (great defect of centre of field). The pupils were equal and active, but the left acted less freely than the right to direct stimulation. The movements of the left eye were perfect, but the palpebral fissure was decidedly narrower than the right, and the lids rather puffy. There was no congestion of the eye; there was doubtful tenderness over supra-orbital notch, but none on pressing the eyeball back into the orbit

With the ophthalmoscope the left disc was seen to be doubtfully redder than the right, but no definite changes could be made out. The retinal vessels in both eyes pulsated with unusually little pressure. There was no evidence of vaso-motor paralysis. He was not rheumatic, nor liable to neuralgia ; had occasionally had a slight "stiff neck." Six years ago he had gonorrhoea ; no proof of syphilis.

On the 18th he was ordered six grains of iodide of potassium, and twenty minims of solution of perchloride of mereury three times a day, and a blister to the left side of the head every night. On the 20th, on getting up he found his sight had begun to improve. On the 3lst, the left eve could read words of 4 Jaeger held close, and $\frac{20}{5} \frac{0}{(b a d}$ light). The fundus as before ; no definite changes.

Nov. 7th. - Right, 1 Jaeger fairly and $\frac{20}{5}$; left, 1 Jaeger at from $9 \mathrm{in}$. to $12 \mathrm{in}$., but not so well as right and $\frac{20}{30}$ Pupils equal and active. Left palpebral fissure still rather narrower than right, but lids not puffy. Had only used five blisters in all

On Jan. 2nd, 1879, he still did not see quite so well with left as right. He read I Jaeger with each but the words "look brighter" with the right than the left. His visual field was not taken carefully, nor was he tested for colours until he could again read 1 Jaeger, when he showed no defect.

\section{WANDSWORTH INFIRMARY.}

SUPPURATIVE OTITIS ; INTRACRANIAL ABSCESS; PY\&MIA; CEREBRO-SPINAI MENINGITIS ; DEATH.

(Under the care of Dr. JAMES ALLEN.)

B. D-, a woman aged nineteen, was admitted on the 6th January, 1880, and died on the 10th. She had been rather deaf from childhood; and since four years of age she had been subject to fits. These came on at intervals of about a year, several then occurring in succession. Six years ago she had disease of the left tibia, which cons. tinued for two years with discharge of pus. Shortly before the present illness she was a donestic servant, and had to give up work on account of increased deafness. Drops for the ears were prescribed on her applicarion at an Ear Infirmary. On the 19th December, 1879, she had pain in both ears. She was now unable to attend the Ear Infiımary, but the pain being increased by the drops, she discontinued them. Intense headache and vomiting soon followed, and the former symptom persisted. When raised in bed she could not hold up her head, and screamed unless it were supported. She had had several fits in the course of her present illness; she became paraplegic about a week before admission, and a few days later complained of pain in the righi chest. The bowels had been regular. She menstruated on Dec. 29th; was unmarried, and had no children. There was a family history of phthisis.

On admission she had motor paralysis of the lower ex. tremities, and seemed to suffer great pain on the slightest mauipulation of the head or spine. During examination she showed much irritahility of temper. The skin was pale, there was no eruption, but the skin was hypersethetic and dry with pungent heat. Tache cérébrale was well marked. Temperature in axilla $1035^{\circ}$. There were sordes on the lips and teeth; the tongue was covered with a dry brown coat, but the edges were clean and red. There was great thirst. The pupils were dilated, equal, and contracted to light; the conjuuctivæ were injected. The girl was very deaf in both ears. The cephalalgia was chitfly frontal, but also general, though not so severe as it had heen. There was rachialgia along the whole length of the spine, increased 